American Journal of Environmental Sciences 5 (4): 526-535, 2009

ISSN 1553-345X

(C) 2009 Science Publications

\title{
Implementation of Environmental Management Systems in the Extraction of Construction Aggregates from Gravel Pit Lakes
}

\author{
Serena Botta, Claudio Comoglio, Alberto Quaglino and Andrea Torchia \\ DITAG-Department of Land, Environment and Geo-Engineering, Politecnico di Torino, \\ C.so Duca Degli Abruzzi 24, 10129 Torino, Italy
}

\begin{abstract}
Problem statement: Mining operations are strategic and essential industrial activities which rely on the use of non renewable natural resources, causing several relevant interactions with the environment. Approach: The need to perform in compliance with even more stringent environmental legislation and to satisfy different stakeholders demands and pressures, is progressively leading the mining sector towards the implementation of Environmental Management Systems (EMS). However scientific literature outlined a relevant research gap in the absence of specific technical guidelines to facilitate such voluntary environmentally responsible approach in the different sectors of mining. Results: Therefore the present study was focused on the extraction of construction aggregates from gravel pit lakes, sector characterized by peculiar operations and related environmental problems. Through the analysis of representative sites (located in Piedmont Region-NW Italy), where the environmental components of the interested territories, the equipments used and operations carried out, the main legal requirements, the environmental problems and monitoring systems were examined, the research identified environmental problems and practices which could be considered common to this sector and be taken into account during the EMS implementation. In particular the study, with reference to the ISO 14001 requirements, focused on the analysis and monitoring of the environmental aspects and to the identification of specific operational and monitoring procedures which should be defined by the organization within the EMS. Conclusion: Therefore the main results of the research presented in this study supplied specific technical elements to be used by the companies operating gravel pit lakes for a correct and exhaustive EMS implementation and represented a new contribution for a more widespread adoption of ISO 14001 in the mining sector.
\end{abstract}

Keywords: Environmental management systems, ISO 14001, environmental review, mining sector, gravel pit lake

\section{INTRODUCTION}

Mining operations are strategic and essential industrial activities on which the economy of several countries is based ${ }^{[19,20]}$; however a significant counterpart of the great socio-economical relevance of the mining sector is its often conflictual relationship with local communities and governmental bodies due to the concerns regarding its impacts upon the environment ${ }^{[1]}$. Even if mining activities are not widespread as other land uses, their location on the territory is a consequence of the presence of geologically fixed mineral deposits which can be exploited and therefore the interaction with ecologically sensitive areas can often not be avoided by selecting alternative sites by means of a preventive adequate planning $^{[1,11]}$; mines are usually located in sites of relatively undisturbed and close-to-nature conditions, increasing the perception of these human activities as an element of intrusion and alteration of the baseline scenario and, therefore, as a cause of relevant environmental impacts. Furthermore, mining disasters with several casualties occurred in the past have raised the perception in the public opinion of mining being an high risk activity for environment, workers and public health: Pressure groups, including some nongovernmental organizations, are drawing international attention to environmental incidents and in several sites local communities protest against and impede or even shut down mines ${ }^{[18]}$.

Mining operations, by their own nature, are generally characterized by several environmental impacts: The occupation of land and "manipulation" of local topography cause changes in land form and

Corresponding Author: Serena Botta, DITAG-Department of Land, Environment and Geo-Engineering, Politecnico di Torino, C.so Duca Degli Abruzzi, 2410129 Torino, Italy Tel: +39 0115647717 Fax: +39 0115647686 
instability, habitat, biodiversity and land uses losses, visual intrusion, modifications in surface and groundwater; pollution can occur from acid mine drainage formation, cyanide and other toxic chemicals (oil, petroleum products, solvents, acids and reagents) release, sediments runoff, emissions to air and fugitive dust emissions, noise, vibrations and traffic. Furthermore, thus mining operations have a transient nature, being related on finite and non renewable mineral deposits, significant environmental impacts are not only related to operational activities, but are still linked to the closure of the site and subsequent reclamation and restoration phases (which are a fundamental mitigation and/or compensation measure).

As mining activities rely on the use of non renewable natural resources and involve several relevant interactions with the environment, a prudent and responsible exploitation is a significant challenge which involves competent authorities (permits release and controls) and mining companies (economically viable planning and operation $)^{[19]}$.

In the light of the above elements, even more stringent environmental compulsory legal requirements and limits to which mining companies have to comply, especially related to the handling of wastes from nonferrous metal mining industry ${ }^{[16]}$, are being defined by several national and regional governmental bodies.

Further pressures upon the mining sector environmental responsibilities are related to the demands of investors and consumers which are interested in good social and environmental practices and companies performances in such fields ${ }^{[18,19]}$.

The need to perform in compliance with environmental legislation and to improve performances in order to satisfy different stakeholders (competent authorities, local communities) demands, is progressively leading the mining sector towards an approach of "cleaner production" and "pollution prevention",[11] aimed at a correct environmental management of the mining sites and related infrastructures. The mining industry has therefore shown increasing interest in environmental and social sustainability in recent years ${ }^{[19]}$. According to the ever increasing complexity of the legal framework and related environmental requirements and prescriptions applicable to the mining sector, the companies are gradually shifting from a conventional "end-of-pipe" pollution control approach towards a more proactive one allowing a proper identification and management of environmental impacts, risks and related liabilities. This proactive approach is based on the implementation of environmental management systems (EMS) which, according to the ISO 14001 standard $^{[12]}$ and/or the
European EMAS Regulation ${ }^{[6]}$, require a detailed review of the organization activities, processes and products aimed at evaluating and continuously improving the related environmental performances, going beyond the "simple" legal compliance. An EMS can therefore be considered a useful tool and management model that helps an organization to identify significant environmental issues, plan and meet environmental goals and comply with environmental regulations $^{[20]}$ and could be adequately integrated with health, safety and social accountability issues ${ }^{[11]}$. Salmi $^{[21]}$ discussed the main drivers, among which regulatory, stakeholders and market pressures, for adopting EMS in the mining industry, with particular regard to the post-Soviet area. Hilson and Nayee ${ }^{[9]}$ identified some main benefits related to the implementation of an EMS to the mining sector: Better knowledge of potential impacts on the environment and applicable legal requirements, reduced operating costs and improved efficiency, improved image and better relationships with competent authorities and local stakeholders due to the voluntary commitment towards the minimization of environmental problems.

Several mines worldwide, mainly owned by multinational corporations, have a comprehensive EMS in place and a number of other sites already have management procedures that would allow an eventual implementation of an EMS ${ }^{[9]}$. Among others, examples of EMS implementation and consequent ISO 14001 certification, are reported from several mines (mainly metals extraction) in Canada, Australia ${ }^{[9]}$, Russia ${ }^{[21]}$, Mexico $^{[20]}$ and in Chile ${ }^{[19]}$, where all the state-owned facilities and over $50 \%$ of the private-owned sites have implemented a certified EMS; among these the world largest open pit (Chuquicamata) and the world biggest copper mine (Escondida).

In Italy 98 sites managed by companies related to the mining sector (not only extraction sites) have obtained the ISO 14001 certification $^{[24]}$. With regards to EMAS, considering the four European countries with the highest number of registered organizations (Germany, Italy, Spain and Austria), 27 sites belong to the mining sector: 1 to mining of hard coal (NACE code 5.1), 23 to quarrying of stone, sand and clay (NACE code 8.1 ) and 3 to other mining and quarrying activities (NACE code 8.9).

Hilson and Nayee ${ }^{[9]}$, highlighting the need to make widespread mining EMS implementation a reality, identified a research gap in the substantial absence of technical guidelines to facilitate specific and detailed implementation in the various sectors of mining, recommending an increased input from academic and government research units, especially focused towards 
small and medium-sized mining companies, many of which already have important environmental management tools in place, but lack the finances, educational material and technological know-how to design and implement an effective EMS.

According to the above mentioned directions, in this study the attention is focused on a specific type of mining activity (for which experience of EMS implementation are not found in the existing scientific literature) characterized by peculiar operational techniques and consequent interactions with the environment: The extraction of construction aggregates from gravel pit lakes.

Sand and gravel deposited by fluvial processes represent a mineral resource of great economic and social value, used by the construction industry for concrete (aggregate mix) for buildings and infrastructures (roads and highways) in large quantities (aggregates usually account for $60-80 \%$ of the total volume of concrete).

In gravel pit lakes such operations require the extraction below the water table and the on-site treatment (screening, separation by size, crushing, washing) of relevant quantities of materials through the use of a dragline, dredging or hydraulic excavators. Their usual localization represents by itself a specific factor of environmental concern, being gravel pit lakes close to watercourses, often in areas of significant naturalistic value (wetlands and protected areas) and which can be interested by flooding.

This study outlines some relevant elements on which companies carrying out the extraction of construction aggregates from gravel pit lakes should focus while implementing an EMS of their activities and can therefore be considered as a technical reference. Such elements arise from the analysis, carried out by the authors, of representative sites located in Piedmont Region (NW Italy) and are mainly focused on the steps which have to be carried out for the definition of an adequate and comprehensive initial environmental review, which is the fundamental phase for the implementation of an efficient EMS, according to ISO 14001 standard and/ or EMAS regulation.

\section{MATERIALS AND METHODS}

The ISO 14001 standard (International Standard Organization, 1996, 2004), the Eco-Management and Audit Scheme (EMAS) Regulation (European Parliament and Council, 2001; European Commission, 2006) were the reference documents used in this study for identifying the key requirements for the EMS implementation $^{[6,12]}$.
In particular the implementation of manual and procedures must be based on the requirements specified by the ISO 14001 standard which is related to the Deming cycle implementation steps (policy and planning, implementation and operation and checking and corrective action) as outlined in Table 1.

Some gravel pit lakes located in Piedmont Region (NW Italy) along the Po river, using different excavation techniques were considered as representative case studies and were consequently analyzed in order to carry out an initial environmental review aimed at identifying the main environmental aspects related to each activity. In particular, for each site the environmental components of the interested territories, the equipments used and operations carried out, the main legal requirements, the environmental problems and monitoring systems were examined.

The main results of these analyses are outlined with specific highlights on relevant contents and issues for the implementation of the procedures related to the EMS planning step, with particular regard to the analysis of environmental aspects.

Since several available implementation guidelines $^{[3,8,13-15]}$ can be considered a sufficient reference for almost every kind of organization for providing the main structure and the basic contents for the definition of the general management procedures (such as those concerning documentation, training, control of documents, nonconformity, internal audit, management review), the analysis of implementation, operation, checking and corrective action phases is omitted within this study.

\begin{tabular}{ll} 
Table 1: EMS implementation steps according to ISO 14001 \\
\hline Step & ISO 14001 \\
\hline & 1. Scope \\
& 2. Normative references \\
& 3. Terms and definitions \\
& 4.1. General requirements \\
& 4.2. Environmental policy \\
& 4.3.1. Environmental aspects \\
Planning & 4.3.2. Legal and other requirements \\
& 4.3.3. Objectives, targets and program (s) \\
Implementation & 4.4.1. Resources, roles, responsibility and authority \\
and operation & 4.4.2. Competence, training and awareness \\
& 4.4.3. Communication \\
& 4.4.4. Documentation \\
& 4.4.5 Control of documents \\
& 4.4.6. Operational control \\
& 4.4.7. Emergency preparedness and response \\
& 4.5.1. Monitoring and measurement \\
Checking and & 4.5.2. Evaluation of compliance \\
corrective action & 4.5.3. Nonconformity, corrective action and \\
& preventive action \\
& 4.5.4. Control of records \\
& 4.5.5 Internal audit \\
& 4.6. Management review \\
\hline
\end{tabular}


On the other hand, with regards to the main operational procedures related to the ISO 14001 phases (operational control and monitoring and measurement), which have to be focused on the peculiarities of the site and of the organization activities, specific elements and issues, whose correct management has to be properly covered by the EMS scope, are outlined as a guidance for implementation in other sites belonging to the same typology of mining operations.

\section{RESULTS}

A fundamental step of the planning stage required by the ISO 14001 standard and the EMAS Regulation is to carry out an initial environmental review to identify the critical environmental issues arising from the organization activities, analyzed in the framework of the wider environmental context (site) where it operates. The environmental review is the fundamental basis for the implementation of the whole EMS and, after the description of the site's environmental peculiarities, it must be carried out identifying, describing and, where feasible, quantifying all the direct and indirect environmental aspects related to the organization activities. This to evaluate the baseline environmental performances from which the continuous improvement should be planned by means of specific objectives and targets.

The review can be divided into five main phases:

- Description of the site's environmental characteristics

- Activities description (including responsibilities and legal requirements definition and description)

- Environmental aspects analysis (including energy and raw materials consumption analysis and abnormal operating conditions definition and description)

- Monitoring systems definition and description

- Documentation of relevant environmental aspects

The description of the site's environmental characteristics is the first step of the initial environmental review and it must be focused on the identification of the more relevant features of the territory interested by the gravel pit lake operations, which can influence and/or be affected by the environmental performances of the site.

For this specific type of mining activities the main key elements to be taken into account are:

- Hydrogeological characteristics: Free and confined groundwater status and dynamics (levels fluctuations and flow directions); water quality (lake and aquifer); existing infrastructures interacting with the groundwater levels (buildings, wells, landfill)

- Hydrological characteristics: Watercourse hydraulic and geomorphological dynamics (focus on extreme events: Low flows and floods); water quality; existing water uses (hydropower, irrigation)

- Main geological, lithological and geotechnical characteristics

- Meteorological data (rainfall, winds, temperatures) and air quality

- Existing land uses (agriculture, forestry, urban settlements, industrial areas, protected areas, recreation

- Presence of anthropic structures and infrastructures (type and distance from the site)

- Access roads and traffic levels

- $\quad$ Existing and maximum allowed noise levels

- Biodiversity (focus on the real/potential presence of protected habitats and threatened flora and fauna species, with particular regards to the river, lake and wetland areas)

- Landscape

These information are usually already available from the technical documentation provided to the competent authorities in order to get the authorization to start operating the site (e.g., Environmental Impact Assessment procedure); therefore to carry out their analysis should not require additional significant costs for the company.

After the description of the site's environmental scenario the analysis must be focused on a detailed description of all the activities carried out in the gravel pit lake, which generally can be summarized into the following ones (this list is not meant to be exhaustive and specific operations type and sequence can slightly differ from site to site):

Site's preparation: Topsoil and subsoil stripping, removal and storage (to be used for site restoration purposes).

Excavation: Excavation of the first layer of gravel and sand above the water table and preliminary transfer and stocking by means of head loaders, conveyor belts or pit haulers; excavation below the water table through redinger, dragline (operating from the banks or pontoons) or dredging; (preliminary washing), transfer and stocking on the lake banks. 
Processing (transfer, washing, screening, crushing, stocking): Excavated material is sent by means of head loaders, conveyor belts or pit haulers and dumpers to a preliminary washing section in order to separate sand from gravel (specific washing sections are further used to classify sands into different gradations) and to single or multi-deck vibrating or rotating screens, each sorting it into two or more size classes stockpiles; according to their final destination larger size materials are sent to a crushing section and then to a secondary washing, (drying) and screening section; the processed material is put into size classes stockpiles.

Shipping: Material is shipped by trailer trucks filled from the stockpiles by front-end loaders.

Restoration: Progressive restoration actions (topsoil and vegetation) in the areas where excavation is completed. The restoration can be finalized only to naturalistic or aesthetic improvements or can foresee several human uses (e.g., sportfishing, aquatic sports, fish farming).

Collateral activities: Activities and infrastructures which are functional to a correct management of all the main operations, e.g., fuel storage and distribution, maintenance operations, offices, employees services and canteen.

A general layout of the site, with the localization of all the equipments, structures and infrastructures have to be provided, together with the plan of future extraction activities up to the site's closure and final restoration.

All the above activities and sub-activities must be described in terms of equipment used and duration according to the phases carried out at the site, with a specific detail on their dimensional and technological peculiarities.

The following fundamental step of the initial environmental review is the identification of the environmental aspects of the activities that the company can control and over which it can be expected to have an influence, in order to determine those which have or can have significant impacts on the environment.

With regards to environmental aspects to be considered a comprehensive list is provided by Annex VI of EMAS Regulation ${ }^{[6]}$ :

- Emissions to air

- Releases to water

- Avoidance, recycling, reuse, transportation and disposal of solid and other wastes, particularly hazardous wastes

- Use and contamination of land
- Use of natural resources and raw materials (including energy)

- Local issues (noise, vibration, odor, dust, visual appearance)

- Transport issues (both for goods and services and employees)

- Risks of environmental accidents and impacts arising, or likely to arise, as consequences of incidents, accidents and potential emergency situations

- effects on biodiversity

Each activity carried out in the gravel pit lake must therefore be analyzed in order to identify if it determines one or more of the above listed environmental aspects. A simple matrix like the one presented in Table 2 can be used in order to summarize the analysis on the relationships existing between activities and environmental aspects.

Each aspect must then be analyzed into details and described in both qualitative and, where applicable, quantitative way.

For this characterization the sub-activities originating the aspect and the possible other subjects involved (e.g., maintenance or shipping carried out by external companies), the environmental and social components affected by the aspect (air, water, soil, flora, fauna, employees, local community), the applicable legal requirements (e.g., maximum allowed noise or pollutants concentration levels), the treatments, mitigation measures and monitoring systems already in place shall be outlined, possibly using standardized matrices (Table 3) where such information can be adequately summarized.

Where other subjects are involved, the company's actual level of control and influence on the related environmental aspect must be adequately evaluated in order to be able to classify the aspect as a direct or an indirect one.

Table 2: Activity/environmental aspects matrix

\begin{tabular}{|c|c|c|c|c|c|c|c|c|c|c|}
\hline \multirow{2}{*}{\multicolumn{2}{|c|}{ Activity }} & \multicolumn{9}{|c|}{ Environmental aspects } \\
\hline & & $\mathrm{a}$ & $\mathrm{b}$ & $\mathrm{c}$ & $\mathrm{d}$ & $\mathrm{e}$ & $\mathrm{f}$ & $\mathrm{g}$ & $\mathrm{h}$ & $\mathrm{i}$ \\
\hline Site's preparation & & $\mathrm{x}$ & & $\mathrm{X}$ & $\mathrm{x}$ & $\mathrm{x}$ & $\mathrm{x}$ & $\mathrm{x}$ & $\mathrm{x}$ & $\mathrm{x}$ \\
\hline Excavation & & $\mathrm{x}$ & & & $\mathrm{x}$ & $\mathrm{x}$ & $\mathrm{x}$ & $\mathrm{x}$ & $\mathrm{x}$ & $\mathrm{x}$ \\
\hline Processing & & $\mathrm{x}$ & $\mathrm{x}$ & $\mathrm{x}$ & & $\mathrm{x}$ & $\mathrm{x}$ & $\mathrm{x}$ & $\mathrm{x}$ & \\
\hline Shipping & & $\mathrm{x}$ & & & & $\mathrm{x}$ & $\mathrm{x}$ & $\mathrm{x}$ & & $\mathrm{x}$ \\
\hline Restoration & & $\mathrm{x}$ & & $\mathrm{x}$ & $\mathrm{x}$ & $\mathrm{x}$ & $\mathrm{x}$ & $\mathrm{x}$ & & $\mathrm{x}$ \\
\hline Collateral activities & $\mathrm{x}$ & $\mathrm{x}$ & $\mathrm{x}$ & $\mathrm{x}$ & $\mathrm{x}$ & $\mathrm{x}$ & $\mathrm{x}$ & $\mathrm{x}$ & $\mathrm{x}$ & \\
\hline
\end{tabular}

Table 3: Environmental aspects basic characterization matrix Environmental aspect:

\begin{tabular}{llllll}
\hline Activity & Subjects & $\begin{array}{l}\text { Affected } \\
\text { env. and } \\
\text { soc. comp. }\end{array}$ & $\begin{array}{l}\text { Legal } \\
\text { req. }\end{array}$ & $\begin{array}{l}\text { Treatments/ } \\
\text { Mitigation } \\
\text { meas. }\end{array}$ & $\begin{array}{l}\text { Monitoring } \\
\text { systems }\end{array}$ \\
\hline$\ldots$ & $\ldots$ & $\ldots$ & $\ldots$ & $\ldots$ & $\ldots$ \\
\hline
\end{tabular}


According to the preliminary review carried out on the case study sites, the following environmental aspects have been identified and, therefore, have to be considered as the more common for usual gravel pit lakes operations and a useful reference for the environmental aspects characterization phase of sites where an EMS is going to be implemented.

Emissions to air: In almost all the main operations carried out in the site sources of emissions are present since several equipments are supplied by fuel (front-end loaders, pit haulers); these could be directly owned and managed by the company or by third parties (e.g., devices for maintenance, trailer trucks). Occasional emissions can be related to motor-generator sets used for supplying electricity in case of emergency. Point sources of air emissions are related to crushing sections where filtration devices limit particulate dispersion. Other point sources are related to heating systems for offices and structures used by employees and canteen equipments (where not supplied with electricity). On the other hand dust emissions are considered within the environmental aspect "local issues".

Releases to water: Washing activities (and the use of water aimed at reducing fugitive dust at the site and along access roads) generate high turbidity waters which are usually sent into dedicated sedimentation ponds or treated in specific sections with the help of chemical additives in order to separate fine suspended particles: Treated waters can then be sent to the lake or to a watercourse or be reused for subsequent washings; in order to prevent excess sediment loads in surface runoff (which could affect the lake and external waterbodies) even other areas within the site must have proper collection systems connecting such discharges to the above sedimentation/treatment devices or to adequate silt fences; other releases, if no recycle is provided, can derive from the treatment of runoff over areas with the potential presence of pollutants (e.g., fuel and oil leakages in maintenance and fuel storage areas); offices and other structures used by employees originate wastewater which usually, being the urban sewage system far from the lake, is treated on-site and afterwards can be used for irrigation purposes in the restored zones or released to water-bodies or subsoil.

Management of wastes: Green waste is originated from site's preparation activities and maintenance of restored areas and can be composted or disposed in landfill. Restoration activities may also produce containers of fertilizers and other chemical additives which have to be adequately managed. Sediments separated from the releases originated during washing activities can be reused on- or off-site or disposed according to their mineralogical composition and to the methods used for their sedimentation ${ }^{[22,23]}$; other wastes are originated from the periodic maintenance of wastewater treatment devices (oil, sludge); a relevant source of hazardous wastes production is the maintenance of the operating devices: Batteries, exhausted oil, filters, paints, other spare parts. Offices and canteen household wastes have to be sorted and sent to the municipal solid waste recycle and disposal system, while a particular attention must be paid to hazardous household wastes like e-waste, light bulbs, fluorescent tubes, medication.

Use of land: Use of land intended as occupation of land and change of land use is intrinsically linked to the mining activities and has to be formally related to site's preparation, excavation and restoration activities, all causing a progressive land use variation in the interested areas. Furthermore occupation of land is related to the presence of structures and infrastructures at the gravel pit lake site. Contamination of land is considered within the environmental aspect "risks of environmental accidents".

Use of natural resources and raw materials: The use of water, directly withdrawn from the lake or wells or local watercourses, is mainly related to washing activities during the processing phase and for mitigating fugitive dust emissions (e.g., sprinkling access roads and stockpiles area during dry and windy days); its reuse after the sedimentation treatment is to be considered a best practice; offices, employees services and canteen cause water consumption as well as water withdrawals for irrigation in restoration activities. Fuel consumption is due to several equipments used in the activities carried out at the gravel pit lake (front-end loaders, pit haulers, trailer trucks), often including also heating and other systems installed in the site buildings. Electricity can be used for excavation operations (e.g., connection to high voltage grid to supply draglines), for minor equipments used in several activities, lighting, monitoring systems and buildings. Photovoltaic modules and solar thermal collectors installed at the site can usefully integrate the electricity and fuel supply demands.

Local issues: The more significant aspects classified as local issues are noise, dust and visual intrusion. Noise is related to most of the activities carried out at the gravel pit lake, with particular relevance in the extraction and crushing phases which can cause a significant increase of the baseline noise levels, especially when operations 
are carried out also during nighttime. While, together with other mitigation measures at source, vegetation along the restored lake banks can act as a barrier, noise originated by trailer trucks can affect external areas and sensitive sites along the access roads.

Fugitive dust emissions, which are mainly related to processing and shipping, are a relevant problem which demands proper mitigation actions, such as air filters at crushing devices, water sprinklers at screens, transfer points and stockpiles, water browser trucks to wet internal and access roads, proper coverage of the trucks load.

Usually gravel pit lakes are located in areas interested by agricultural uses or characterized by relevant naturalistic values, close to wetlands and watercourses: Therefore the structures, equipments, stockpiles, access roads and, in general, the activities carried out in the site represent a relevant element of visual intrusion which alters the baseline scenario. Restoration actions during the site operation shall (also) be focused to progressively mitigate this impact, at least with reference to the main viewpoints. Another possible element of visual intrusion to be taken into account is represented by possible nighttime operations, during which lighting have to be provided.

Transport issues: Increased traffic at local level is related to employees and external services companies vehicles access to the workplace and, mainly, to the shipping of the aggregates by means of trailer trucks.

Risks of environmental accidents: Leakage of pollutant substances (oil, fuel) can occur within the lake or other areas, affecting surface and/or groundwater and/or soil, because of accidental damages of oilpressure circuits, malfunction or employees errors in specific operations like fuel distribution. Other potential risks can be related to malfunctions occurring to wastewater treatment devices or air filters.

Stability of lake banks must be adequately monitored over short and long term in order to avoid safety and environmental risks during operations and future fruition of the site.

Flood events can directly involve the site, affecting areas where wastes and pollutant substances are stocked and causing their dispersion into the environment. Furthermore existing structures can constitute an obstacle to the downstream flow of flood discharges with consequent potential safety risks to surrounding areas.

Effects on biodiversity: usually the sites where gravel pit lakes are located, close to wetlands and watercourses, are characterized by the presence of several faunal species of naturalistic interest (e.g., migratory birds, amphibians, small mammals) and therefore the disturbance caused by noise, dust, increased road traffic and, in general, human presence could cause relevant impacts and the abandonment of the interested areas. New access roads and the progressive extension of the extraction areas generally cause an impact upon vegetation, which have to be removed and a possible fragmentation of the ecosystems (e.g., migratory routes of amphibians). Existing vegetation along the site and access roads can be affected by dust deposition; water table variations (upstream decrease and downstream increase) around the gravel pit lake can alter the composition in species of the vegetation and, in some cases, affect (i.e., drying) wetlands and species which rely on these fragile habitats. Agricultural land represents a potential source of nutrients concentration increase in the gravel pit lakes, which could lead to eutrophication processes: adequate diversion and collection systems for surface runoff from external areas have therefore to be provided in order to prevent such environmental problem which affect several sites ${ }^{[5,7]}$.

Starting from the review of the possible environmental aspects usually associated to gravel pit lake operations, the ones applicable to the examined site shall be identified and their analysis will have to be carried out into details using the approach outlined in Table 3 (adequately adapted to the peculiarities of each aspect).

The identified aspects must then be evaluated by the organization in order to define their significance (i.e., aspect which has or can have a significant environmental impact), by defining and applying specific significance criteria, which shall include the fragility of the environmental components which can be affected by the aspect, the potential to cause environmental harm, the size and frequency of the aspect, the existence and requirements of applicable environmental legislation and the importance of the aspect to the employees, local communities and stakeholders.

Significant environmental aspects are the key outcome of the environmental review and must then be adequately considered for the following step of the EMS implementation: The definition of environmental objectives and targets to be planned defining means, resources, responsibilities and deadlines for their achievement within the environmental program.

Within the consequent EMS implementation of manual and procedures, aspects related to operational control and monitoring play a relevant role for a proper management of the gravel pit lake environmental 
issues. Hilson and Nayee ${ }^{[9]}$ outlined the requisite components and the main guidelines for implementing a comprehensive mining EMS, focusing on the relevance of internal responsibilities assignment, employees training, external communication, audit and corrective action; however the provided elements are related to the implementation of the general aspects of the EMS within the wide scenario of the mining sector and do not address into details the management of specific environmental issues.

In relation to the gravel pit lake operations, based on the analysis of the examined case studies, among the operational procedures which can be specifically issued and applied the following can be highlighted, listed in a logical order according to the environmental aspects list:

- Monitoring of fuel and electricity consumption and conversion into equivalent carbon dioxide emissions (balance at site level)

- Maintenance plan of all the equipments supplied by fuel

- Crushing section filters control plan

- Heating plant maintenance and emissions monitoring plan

- Monitoring plan of water quality (suspended solids, dissolved oxygen, nutrients) at the releases from the sedimentation/treatment devices

- Sedimentation/treatment devices maintenance and related wastes management plan (a specific operational procedure can be issued for the management of sediments)

- Monitoring plan of groundwater levels and quality upstream and downstream the gravel pit lake;

- Monitoring plan of gravel pit lake levels and quality (a special focus on eutrophication levels)

- Wastes management and monitoring plan

- Water consumption monitoring plan

- Noise monitoring plan (at sensitive receptors outside site's boundaries and along access roads);

- Management of internal traffic (speed limits, trucks coverage, engines shut down at stops)

- Fugitive dust emissions management plan (and monitoring at sensitive sites)

- Restoration activities plan and efficiency monitoring (e.g., vegetation growth, amphibians, fish, mammals and birds species presence, visual impact mitigation)

- Emergency management and intervention plan (leakages, malfunctioning of treatment devices)

- Banks stability monitoring plan (topographic and bathymetric surveys)
Some of the above operational procedures can be unified into a single one (e.g., issue of a maintenance plan which covers all the devices and equipments of the gravel pit lake) in order to limit the personnel efforts in EMS documentation control and management.

\section{DISCUSSION}

Environmental concerns about mining activities and increasing stakeholders pressures and demands are leading this industrial sector towards a proactive approach of "cleaner production" and "pollution prevention" based on the implementation of Environmental Management Systems (EMS). Even if the number of mining companies which have already obtained an environmental certification according to the ISO 14001 standard is increasing (but still mainly related to multinational corporations and metals extraction sites), a research gap has been identified by a recent study ${ }^{[9]}$ in the lack of technical guidelines specifically addressing the EMS implementation in the various sectors of mining. These guidance elements are seen as fundamental for a widespread implementation of such environmentally responsible management approach in all types of mining activities, which, even if at different relevance levels, use non renewable natural resources and impact several environmental components. Within the present study, the specific sector of the extraction of construction aggregates from gravel pit lakes has been taken into account through the evaluation of case study sites, supplying technical elements for a correct and exhaustive EMS implementation. Since the main structure and the basic contents for the definition of the general management procedures (such as those concerning documentation, training, control of documents, nonconformity, internal audit, management review) can be easily adapted from existing generic manuals ${ }^{[3,8,14,15]}$ applicable to every kind of small and medium enterprises, in this study specific elements which are peculiar of the examined type of mining operations were considered. In particular the analysis has been focused on the correct development of the environmental review, which is at the basis of the EMS implementation; in fact only an exhaustive and detailed evaluation of the state-of-theart of the environmental performances related to each activity carried out by the organization can lead to the identification of the relevant environmental issues on which the continuous improvement can be planned. The proposed methodology supplies basic helpful elements for a company that wants to implement the main steps of the initial environmental review: Description of site's environmental characteristics, activities and legal 
requirements, identification and significance evaluation of environmental aspects.

Furthermore, in relation to the following steps of the Deming cycle, on which the ISO 14001 is based, i.e., implementation and operation and checking and corrective action, a list of specific operational procedures which could be implemented in a gravel pit lake was provided. Such elements are a basic reference for a sitespecific implementation of operational procedures and help companies to better address efforts in defining proper management and operational tools of their EMS.

Therefore the results of this study can be considered as a basic reference for the EMS implementation in this specific sector of mining operations, which, even if not characterized by the presence of relevant polluting substances, can have significant environmental impacts due to its interferences with surface and groundwater and its usual localization in sites of ecological interest.

A wider implementation of ISO 14001 in this sector will determine several positive implications for a better environmental safeguard and a more adequate management of such operations. Furthermore it can be said that, as the market trends are even more focused on green products and green procurement and the design and construction of sustainable buildings (or green buildings) is an increasing challenge for the construction industry, the supply of high-quality aggregates from sites where a certified EMS is in place can soon become a key element for guaranteeing the environmental sustainability and economical viability of gravel pits lakes.

\section{REFERENCES}

1. Sengupta, M., 1993. Environmental Impacts of Mining: Monitoring, Restoration and Control. CRC Press, ISBN: 0873714415, pp: 494.

2. International Standard Organization, 1996. ISO 14001 environmental management systemsrequirements with guidance for use. http://www.iso.org/iso/iso_catalogue/catalogue_tc/ catalogue_detail.htm?csnumber $=23142$

3. Jackson, S.L., 1997. The ISO 14001 Implementation Guide: Creating an Integrated Management System. John Wiley and Sons, ISBN: 10: 0471153605, pp: 280.

4. Quaglino, A., S. Ratto, E. Comino and C. Comoglio, 1999. Analisi ambientale iniziale di siti di estrazione di inerti sotto-falda. GEAM, 98: 209-216.

5. Kattner, E., D. Schwarz and G. Maier, 2000. Eutrophication of gravel pit lakes which are situated in close vicinity to the river donau: Water and nutrient transport. Limnologica, 30: 261-270. DOI: $10.1016 /$ S0075-9511(00)80057-2
6. European Parliament and Council, 2001. Regulation (EC) No 761/2001 allowing voluntary participation by organizations in a community EcoManagement and Audit Scheme (EMAS). http://eurlex.europa.eu/LexUriServ/LexUriServ.do?uri=OJ: L:2001:114:0001:0029:EN:PDF

7. Sayer, C.D. and N. Roberts, 2001. Establishing realistic restoration targets for nutrient-enriched shallow lakes: Linking diatom ecology and palaeoecology at the Attenborough Ponds, UK. Hydrobiologia, 448: 117-142. DOI: 10.1023/A:1017597221052

8. Stapleton, P.J. and M.A. Glover, 2001. Environmental management systems: An implementation guide for small and medium-sized Organizations. NSF International, pp: 1-201. http://yosemite.epa.gov/water/owrccatalog.nsf/e67 3c95b11602f2385256ae1007279fe/7c3822f9d489d b0185256d83004fd7cb!OpenDocument\&Click=

9. Hilson, G. and V. Nayee, 2002. Environmental management system implementation in the mining industry: A key to achieving cleaner production. Int. J. Miner. Process., 64: 19-41. http://cat.inist.fr/?aModele $=$ afficheN\&cpsidt $=1345$ 9848

10. Hilson, G. and R. van der Vorst, 2002. Technology, managerial and policy initiatives for improving environmental performance in smallscale gold mining industry. Environ. Manage., 30: 764-777.

http://cat.inist.fr/?aModele $=$ afficheN\&cpsidt $=14037867$

11. Hilson, G., 2003. Defining cleaner production and pollution prevention in the mining context. Miner. Eng., 16: 305-321.

http://cat.inist.fr/?aModele $=$ afficheN\&cpsidt $=1467$ 3667

12. International Standard Organization, 2004. ISO 14001 environmental management systemsrequirements with guidance for use. http://www.iso.org/iso/catalogue_detail?csnumber $=31807$

13. Anon., 2004. ISO 14001 registration growing in the mining sector. CIM Bull., 97: 16-17.

14. Euromines, 2005. The ultimate SME implementation guide for ISO 9001:2000 and ISO 14001: 2004 management systems. http://www.euromines.org/publications_downloads /general.pdf

15. Euromines, 2005. The ultimate SME implementation guide for ISO 9001:2000 and ISO 14001: 2004 management systems. http://www.euromines.org/publications_downloads /ISO_14001_2004.pdf 
16. European Commission, 2006. Directive (EC) No $21 / 2006$ on the management of waste from extractive industries and amending directive 2004/35/EC. http://eurlex.europa.eu/LexUriServ/LexUriServ.do?uri=OJ: L:2006:102:0015:0033:EN:PDF

17. European Commission, 2006. Regulation (EC) No 196/2006 amending Annex I to Regulation (EC) No 761/2001 of the European Parliament and of the Council to take account of the European Standard EN ISO 14001:2004 and repealing Decision 97/265/EC. http://eurlex.europa.eu/LexUriServ/LexUriServ.do?uri=OJ: L:2006:032:0004:0012:EN:PDF

18. Horowitz, L., 2006. Editorial-section 2: Mining and sustainable development. J. Clean. Prod., 14: 307-308. doi:10.1016/j.jclepro.2005.03.005

19. Newbold, J, 2006. Chile's environmental momentum: ISO 14001 and the large-scale mining industry-Case studies from the state and private sector. J. Clean. Prod., 14: 248-262. doi:10.1016/j.jclepro.2004.05.010

20. Suppen, N., M. Carranza, M. Huerta and M.A. Hernandez, 2006. Environmental management and life cycle approaches in the Mexican mining industry. J. Clean. Prod., 14: 1101-1115. doi:10.1016/j.jclepro.2004.12.020
21. Salmi, O., 2008. Drivers for adopting environmental management systems in the postSoviet mining industry. Int. Environ. Agreements Polit. Law Econ., 8: 51-77. http://direct.bl.uk/bld/PlaceOrder.do?UIN=224256 230\&ETOC $=\mathrm{RN} \&$ from $=$ searchengine

22. Menatti, M. and R. Vismara, 2008. Valutazione di Impatto Ambientale risultante dalle attività di cava in falda: Stato dell'arte-I Parte. IA Ingegneria Ambientale, $\quad$ 12: 576-590. http://www.cipaeditore.it/img_up/IA\%2012_2008menatti-3.pdf

23. Menatti, M. and R. Vismara, 2009. Valutazione di Impatto Ambientale risultante dalle attività di cava in falda: Stato dell'arte-II Parte. IA Ingegneria Ambientale, $\quad 1-2$ : 46-54. http://www.cipaeditore.it/img_up/IA\%2012_2009-Menatti-3.pdf

24. Sincert, 2009. List of Organizations with management system certified under Sincert accreditation.

http://www.sincert.it/documentisincert.asp?id=256 